\title{
Giant Bladder Stone and Renal Failure: A Case Report, Literature Review and Future Perspectives
}

\section{André Luiz Lima Diniz, Rodrigo Ribeiro Vieiralves, Tomás Accioly de Souza, Luciano Alves Favorito*}

Department of Urology, Lagoa Federal Hospital, Rio de Janeiro, Brazil

Email: *lufavorito@yahoo.com.br

How to cite this paper: Diniz, A.L.L., Vieiralves, R.R., de Souza, T.A. and Favorito, L.A. (2017) Giant Bladder Stone and Renal Failure: A Case Report, Literature Review and Future Perspectives. Open Access Library Journal, 4: e3332.

http://dx.doi.org/10.4236/oalib.1103332

Received: December 26, 2016

Accepted: January 20, 2017

Published: January 23, 2017

Copyright $\odot 2017$ by authors and Open Access Library Inc.

This work is licensed under the Creative Commons Attribution International License (CC BY 4.0).

http://creativecommons.org/licenses/by/4.0/

\section{(c) (i) Open Access}

\begin{abstract}
We present a male patient, 52 years old, with acute renal failure due to giant bladder stone. In first presentation with acute renal failure, tomography has shown a bladder stone with $10 \mathrm{~cm}$ in its largest diameter associated with bilateral ureterohydronephrosis. It was initially treated by bladder catheterization and indicated emergency dialysis and subsequently submitted to surgical treatment through open cistolitotomy. During the procedure it was possible to observe the giant calculus, adhered to the trigone of the bladder, occluding his neck. After the vesical catheter was deployed, the patient had clinical and laboratory improvement during hospitalization. The association between giant bladder stones and urologic kidney failure is a rare condition and once removed the causative factor, we expect the return to normal limits. Studies with higher levels of evidence are needed to increase knowledge about the subject.
\end{abstract}

\section{Subject Areas \\ Urology}

\section{Keywords}

Giant Bladder Stone, Renal Failure, Open Cystolithotomy

\section{Introduction}

In times of technological advances in urology, the entity described in this article goes back to the beginnings of our specialty. Bladder stones represent $5 \%$ of urinary tract lithiasis and the so called Giant is described as stones heavier than 100 
grams (g) or measuring more than 4 centimeters $(\mathrm{cm})$ in its largest diameter [1] [2] [3]. The biggest vesical calculus described weighted $6294 \mathrm{~g}$ [1]. It is a rare condition and reports in literature are limited to cases and description of its various complications. In this context, our objective is to report a case of giant bladder calculi associated with renal insufficiency and conduct a comprehensive literature review.

\section{Scenario and Case Presentation}

This study was carried out in accordance with the ethical standards of the hospital's institutional committee on human experimentation and the Informed consent was obtained from the patient.

A man with previous history of trauma at age 18, suffered pelvis fracture and needed cystostomy; had a good recovery, catheter was removed, but developed voiding dysfunction. At age 52, he needed health care for acute urinary retention associated with renal failure. Transurethral bladder catheterization was performed successfully but high levels of serum creatinine $(6.3 \mathrm{mg} / \mathrm{dL}-$ reference values: $0.7-1.3 \mathrm{mg} / \mathrm{dL}$ ) led him to dialysis.

Tomography (CT) identified a giant bladder stone, $1222 \mathrm{UH}$ (units Hounsfield), measuring $10.74 \times 7.77 \times 5.88 \mathrm{~cm}$, bilateral ureterohydronephrosis and a hypodense image in upper right lateral bladder wall with subcutaneous extension, suggesting cutaneous fistula (Figure 1).

We performed cystolithotomy by transverse incision above the pubic bone, with a longitudinal opening of the bladder. Considering the location that the calculus was encrusted, we performed $623 \mathrm{~g}$ stone extraction after careful dissection of the bladder neck and ureteral ostia identification. Bladder cystostomy with a $22 \mathrm{~F}$ catheter was performed under direct vision; synthesis of bladder in two planes was done after hemostasis review. The stone is shown in Figure 2.

On the second postoperative day the use of antibiotics was suspended according to the guidance of the Center for Control of Nosocomial Infection. Three days later, an operative wound infection, treated with oxacillin for 10 days, was identified. After gradual improvement of renal function (creatinine levels-2.8 $\mathrm{mg} / \mathrm{dL}$ to $2.1 \mathrm{mg} / \mathrm{dL}$ in one week, to $1.98 \mathrm{mg} / \mathrm{dl}$ in five weeks), he was discharged

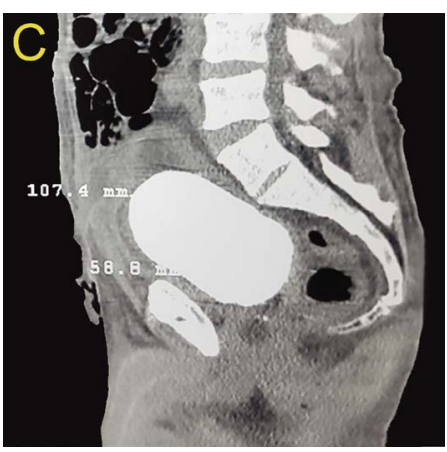

(a)

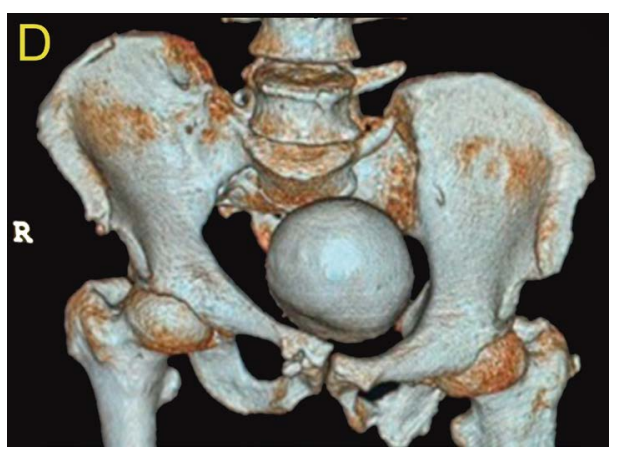

(b)

Figure 1. The figure shows the patient's CT. (a) Stone perspective on sagittal plane; (b) Stone perspective on $3 \mathrm{D}$ reconstruction. 


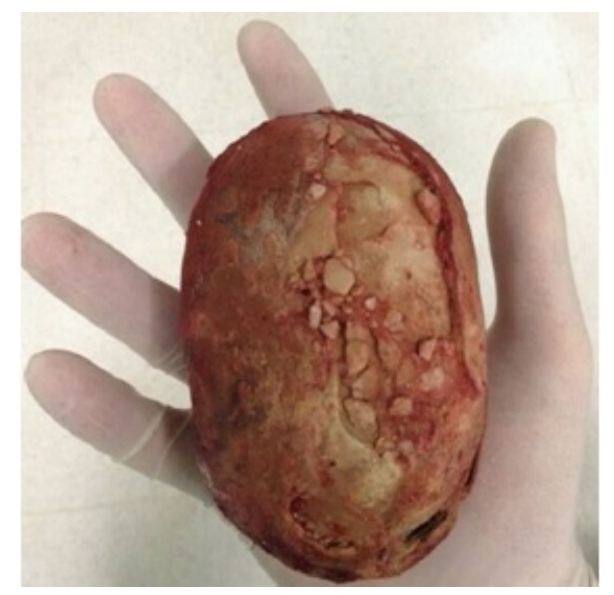

Figure 2. The figure shows the Giant vesical stone after the surgery.

from dialysis. On the 12th postoperative day, the patient developed a vesicocutaneous fistula with conservative treatment through bladder catheterization. In the late postoperative period, an urethrocystography revealed urethral stenosis, a cone-trabeculated bladder shape during voiding attempt. After identification of the stenosis, he underwent termino-terminal urethroplasty. At the moment it has no voiding complaints with a good urinary flow ( $Q_{\max } 43 \mathrm{ml} / \mathrm{s}$ ), and good bladder capacity (Vol $600 \mathrm{ml}$ ).

Due to the rarity of this condition, we investigated similar cases on the following search platform: Pubmed, Research Gate, Virtual Health Library and tried to document its epidemiology, diagnosis, complications and management. By our observation through the indexed platforms, we confirmed the scarcity of this subject.

\section{Discussion and Future Perspectives}

Bladder stones account for about $5 \%$ of urinary tract stones, men are more affected than women [2]. It occurs more commonly in patients of low socioeconomic condition of underdeveloped countries [3].

Children with nutritional disorders are at high risk of developing the called endemic bladder stones. Deficiency of magnesium, phosphate, Vitamin A and B6, combined with low protein content and high volume of carbohydrates are associated to this condition [2].

Boys are more commonly affected than in girls at a ratio of 8:1 [4], common age of occurrence is 2 - 5 years. Our review concerning about giant bladder stones leading to renal insufficiency showed only three cases in children; all them were boys, mean age 9.66 years old, corresponding to $9.67 \%$ of the subjects reported.

Anatomical disorders could lead to bladder stone formation among children. A report by Cuban researches described an 11 year old boy with multiples episodes of urinary tract infection (UTI). Excretory urography was performed: a big radiopaque imaging in pelvis, delay in contrast elimination, bilateral ureterohydronephrosis, an important dilation of the bladder neck above the striated 
sphincter (typical in posterior urethral valve type III by Young's Classification). Open cystolithotomy and debridation of the valve by passing catheters in both ways was performed. Stone weighted $230 \mathrm{~g}$. Patient had a good evaluation and was discharged with good urinary flow and normal renal function [5].

Descriptions of giant calculus in women are rare. We found two cases of women with giant bladder stones causing renal failure, representing $6.45 \%$ of the cases. It is often related with foreign body, sutures, catheters or other objects introduced in the bladder, but also neurological disorders, dystopias and other unusual situations reported in literature. Kidney stones if dropped in bladder may remain as foreign body and attains larger size due to deposition of phosphates around it [6].

Men are commonly affected as $95 \%$ by vesical calculus if compared to women [2]; in our review, $93.54 \%$ of the cases had male patients with giant bladder stones leading to renal impairment. Median age among adult men was 57.88 years, one report didn't show patient's age; our patient was 52 years old. Many causes could lead to bladder stone formation among men, such as prostate enlargement, urethral strictures, neurological disorders, presence of foreign body inside the bladder or even a descendent kidney stone. Our review showed 4 cases related to neurological disorders including neurogenic bladder, multiple sclerosis, spinal cord injury, Parkinson's disease and stroke. In 6 reports we identify low urinary tract symptoms (LUTS) and 7 cases had UTI associated. Some papers related foreign bodies in men and one case showed even recurrence of giant bladder stone. Our patient had voiding disfunctions after pelvic fracture.

The chemical composition of the stones is varied. Colonization status of the urinary tract plays a role on stone formation. Urease-positive organisms predisposes the composition of struvite stones (magnesium ammonium phosphate) and carbonate apatite. Escherichia coli is associated with formation of calcium oxalate stones and urate [7]. In the present case mineralogical study was not done. In the review, 11 cases did not informed about stone's mineralogy. As usual, some of them had more than one mineral in the same stone, 7 papers reported multi-mineral composition; 3 cases showed struvite stones, 4 cases described uric acid, 7 cases listed calcium oxalate, 6 cases exposed calcium phosphate; 1 case reported carbon apatite [8].

The initial suspicion departs from urinary complaints related to the urothelial tract injury associated with history of urinary disorders or manipulation of the urinary tract and pelvis. Diagnostic tools should be employed, starting with the plain radiograph of the abdomen, ultrasound of the urinary tract and cystoscopy [7]. In our case, CT was the method of choice, due to patient's presentation and the presence of a palpable mass in the hypogastrium.

The choices for treatment depend on etiology and size of calculus; various techniques may be employed. Minimally invasive choices like extracorporeal lithotripsy are available but it does not appear to have a good result in calculi greater than $2 \mathrm{~cm}$ [9] [10]. Surgical techniques, endo-urological or open, approaches have a main role in giant bladder calculosis. 
Percutaneous techniques have shown to be safe and feasible, especially in patients without clear urethral access and children. The procedure consists of approaching the bladder by a suprapubic puncture, creation of a path to insert an Amplatz sheath or a trocar, then the endoscopic lithotripsy is performed with lithotritor ultrasonic, pneumatic or even by laser energy [11].

Torricelli and colleagues from São Paulo performed a metanalysis regarding bladder stones treatment; they proposed some guidance and as seen in the chart bellow (Figure 3), the size of the stone influences the way it will be approached [10].

Mean weight among cases reviewed was $428.14 \mathrm{~g}$, the heaviest were $1640 \mathrm{~g}$; mean size in the longest diameter was $8.38 \mathrm{~cm}$, the bigger one had $17 \mathrm{~cm}$ in the longest diameter. The stone in this case was $623 \mathrm{~g}$.

Majority of the cases were managed by open cystolithotomy, it was the only intervention described in 10 cases reviewed, and it means that in $34.48 \%$ of the cases, only one procedure could solve patient's disease. Our patient underwent by urethral catheterization, haemodialysis, open cystolithotomy and cystostomy.

In cases like shown in this paper, the main outcome desired is patient's recovery of renal function. In our review some authors did not described the final serum creatinine values; 7 described as "normal". In one case a patient did not recovered the renal function even six months after surgery [12]-[15]. Our patient recovered renal function and was discharged from dialysis after reach creatinine level of $1,98 \mathrm{ng} / \mathrm{d}$. In our review, considering those who described serum creatinine after treatment, the mean was $2.58 \mathrm{mg} / \mathrm{dL}$.

We clarify that readers could learn that giant bladder stones can lead to complications and renal impairment is a major one. Despite the diagnostic method, treatment should be immediate to avoid complications in short term. Preoperative care such as antibiotic therapy, dialysis and urinary diversion seems to be a good way recovery; but such measures should not delay the cystolithotomy.

\section{Conclusions}

As take-home message we concluded that few studies have reported the relationship between bladder giant stone and kidney failure. Studies with higher

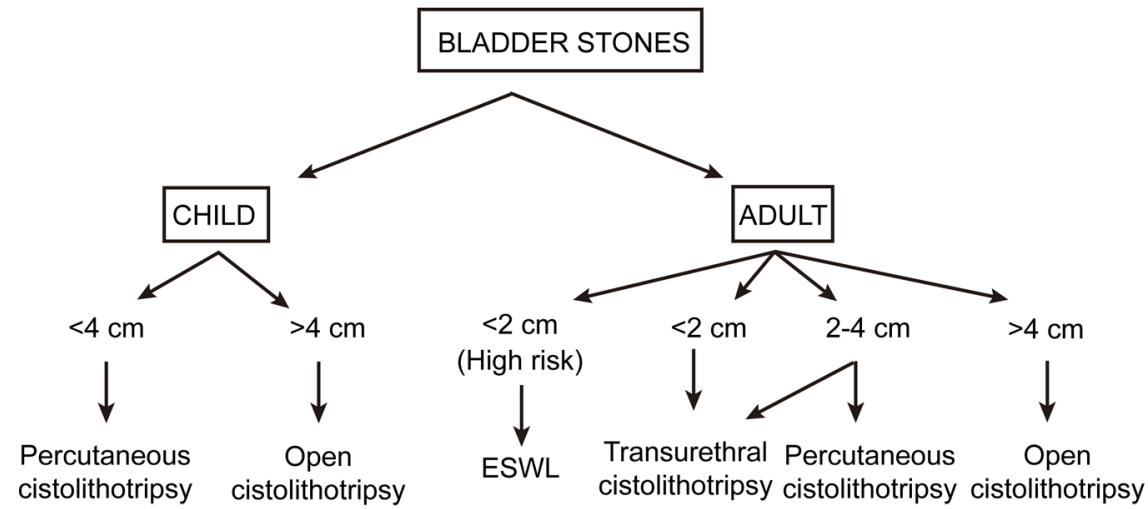

Figure 3. Treatment options according to stone size. 
levels of evidence are needed to increase knowledge about the subject.

Bladder stones are movable, so rarely obstruct urethral or ureteral orifices, but over time, the mineral deposit determines the increase of stone volume, shaping bladder anatomy which can then block the normal urine output, causing renal failure. More studies on imaging should be done in order to understand these obstructions mechanisms. By our observation we conclude that considering the mean bladder volume, calculus greater than $400 \mathrm{~g}$ may be associated with renal failure.

The main parameter used to suppose renal insufficiency is the serum creatinine and urea levels; but, if possible, renal cintilography should be performed and would give us more data about renal impairment. It also would be an important tool to follow the renal function.

Despite the diagnostic method, treatment should be immediate to avoid complications in short term. Preoperative care such as antibiotic therapy, dialysis and urinary diversion seems to be a good way recovery; but such measures should not delay the cystolithotomy.

As final regard, imaging follow up and urodynamics study would be useful to predict recurrence and understand the reasons of bladder stone formation.

\section{References}

[1] Arthure, H. (1953) A Large Abdominal Calculus. Journal of Obstetrics and Gynaecology of the British Empire, 60, 416. https://doi.org/10.1111/j.1471-0528.1953.tb14080.x

[2] Schwartz, B.F. and Stoller, M.L. (2000) The Vesical Calculus. Urologic Clinics of North America, 27, 333-346. https://doi.org/10.1016/S0094-0143(05)70262-7

[3] Trinchieri, A. (2008) Epidemiology of Urolithiasis: An Update. Clinical Cases in Mineral and Bone Metabolism, 5, 101-106.

[4] Agrawal, M.S., Aron, M., Goyal, J., Elhence, I.P. and Asopa, H.S. (1999) Percutaneous Suprapubic Cystolithotripsy for Vesical Calculi in Children. Journal of Endourology, 13, 173-175. https://doi.org/10.1089/end.1999.13.173

[5] Martínez, G.G.J., Sánchez, I.M., Martínez, L.R., Sabian, H.H. and Guerra, D.E. (2000) Litiasis vesical gigante en un niño. Presentación de un caso. Multimed [Internet], 4. www.multimedgrm.sld.cu/articulos/2000/v4-4/12.html

[6] Stav, K. and Dwyer, P.L. (2012) Urinary Bladder Stones in Women. Obstetrical \& Gynecological Survey, 67, 715-725. https://doi.org/10.1097/OGX.0b013e3182735720

[7] Wein, A.J., Kavoussi, L.R., Novick, A.C., Partin, A.W. and Peters, C.A. (2012) Evaluation and Medical Management of Urinary Lithiasis. In: Ferrandino, M.N., Pietrow, P.K. and Preminger, G.M., Eds., Campbell-Walsh Urology, Elsevier, Philadelphia, 1320-1321.

[8] Chiovaro, J. and Minter, J. (2014) Renal Failure with a Large Bladder Calculus Related to a Foreign Body: A Case Report. Clinical Case Reports, 2, 48-50. https://doi.org/10.1002/ccr3.52

[9] Bhatia, V. and Biyani, C.S. (1993) Extracorporeal Shock Wave Lithotripsy for Vesical Lithiasis: Initial Experience. British Journal of Urology, 71, 695-699. https://doi.org/10.1111/j.1464-410X.1993.tb16068.x

[10] Torricelli, F.C.M., Mazzucchi, E., Danilovic, A., Coelho, R.F. and Srougi, M. (2013) 
Tratamento cirúrgico da litíase vesical: revisão de literatura. Revista do Colégio Brasileiro de Cirurgiões, 40, 227-233.

https://doi.org/10.1590/S0100-69912013000300011

[11] Sofer, M., et al. (2004) Refinements in Treatment of Large Bladder Calculi: Simultaneous Percutaneous Suprapubic and Transurethral Cystolithotripsy. Urology, 64, 651-654. https://doi.org/10.1016/j.urology.2004.04.067

[12] Saito, S., et al. (1994) Prolonged Exposure to Intravesical Foreing Body Induces a Giant Calculus with Attendant Renal Dysfunction. Nippon Hinyōkika Gakkai Zasshi, 85, 1777-1780. https://doi.org/10.5980/jpnjurol1989.85.1777

[13] Nygaard, E. and Terjesen, T. (1976) Giant Vesical Calculus and Anuria. Scandinavian Journal of Urology and Nephrology, 10, 88-90.

https://doi.org/10.3109/00365597609179662

[14] Becher, R.M., Tolia, B.M. and Newman, H.R. (1978) Giant Vesical Calculus. JAMA, 239, 2272-2273. https://doi.org/10.1001/jama.1978.03280480064024

[15] Madjar, S., Moskovitz, B., Kastin, A., Stein, M. and Nativ, O. (1996) Anuria and Acute Renal Failure Caused by Multiple Bladder Calculi. International Urology and Nephrology, 28, 639-641. https://doi.org/10.1007/BF02552158

Submit or recommend next manuscript to OALib Journal and we will provide best service for you:

- Publication frequency: Monthly

- 9 subject areas of science, technology and medicine

- Fair and rigorous peer-review system

- Fast publication process

- Article promotion in various social networking sites (LinkedIn, Facebook, Twitter, etc.)

- Maximum dissemination of your research work

Submit Your Paper Online: Click Here to Submit

Or Contact service@oalib.com 